\title{
Left Atrial Mass Demonstrated during Endobronchial Ultrasound Session
}

\author{
Erdoğan Çetinkaya ${ }^{a} \quad$ Aydın Yılmaz ${ }^{b} \quad$ Akif Özgül ${ }^{a} \quad$ Atayla Gençoğlu ${ }^{a}$ \\ Gülşah Günlüoğlua \\ ${ }^{a}$ Yedikule Göğüs Hastalıkları ve Göğüs Cerrahisi Eğitim ve Araştırma Hastanesi, İstanbul, ve \\ ${ }^{b}$ Atatürk Göğüs Hastalıkları ve Göğüs Cerrahisi Eğitim ve Araştırma Hastanesi, Ankara, Türkiye
}

A 59-year-old female patient was admitted to the clinic with a three-month history of dry cough and dyspnoea.

Her chest roentgenogram revealed mediastinal and bilateral hilar widening and a heterogenous density on the right lower zone. Lung function tests showed a restrictive pattern.

A CT of the thorax showed multiple mediastinal and hilar lymphadenopathy and complete right middle lobe collapse but no signs of parenchymal disease. There was a homogenous mass in the left atrium (fig. 1). Bronchoscopy revealed a normal bronchial tree without any endobronchial lesion. We performed transbronchial needle aspiration (TBNA) and took pathological samples from the left hilar, left inferior paratracheal and subcarinal stations under the guidance of convex probe endobronchial ultrasound (CP-EBUS; BF 240 EU-ME1, Olympus, Tokyo, Japan). During the session, we evaluated the left atrium through the anteromedial wall of the intermediate bronchus and the medial wall of the left main bronchus. A well-defined, mobile, hyperechogenic mass was demonstrated (fig. 2). It was $30 \times 40 \mathrm{~mm}$ in diameter, localized in the left atrium and attached to the interatrial septum with a peduncle.

Informed consent was obtained. Cytopathological studies showed non-caseating granulomatous lymphad- enitis in favour of sarcoidosis. The patient was diagnosed as having stage I sarcoidosis. She underwent surgical resection of the atrial mass (online supplementary video 1 , www.karger.com/doi/10.1159/000319701). The definitive diagnosis was left atrial myxoma (fig. 3).

Real-time EBUS-guided TBNA has been shown to be diagnostic in a variety of pulmonary diseases affecting the mediastinal and hilar lymph nodes. It has been shown to be an accurate technique, especially in the diagnosis of stage I sarcoidosis $[1,2]$. We did not perform transbronchial biopsy because of the high diagnostic yield of EBUSguided TBNA and lack of parenchymal disease.

EBUS can be used to assess other mediastinal structures. Left atrium and proximal portions of great arteries can be visualized through CP-EBUS $[3,4]$. We demonstrated the left atrial mass during an EBUS session primarily performed for mediastinal lymphadenopathy. We suggest that all neighbouring structures of large airways should be evaluated, in order to detect any asymptomatic congenital anomalies (e.g. atrial septal defect), acquired cardiac diseases (e.g. valvular heart disease, masses and thrombi) and vascular pathologies (e.g. pulmonary thromboembolism). Incidental findings on EBUS must be confirmed by appropriate tests (i.e. contrast CT scan, echocardiography).

\section{KARGER}

Fax +41613061234 E-Mail karger@karger.ch www.karger.com
(C) 2010 S. Karger AG, Base 0025-7931/11/0811-0057\$38.00/0

Accessible online at: www.karger.com/res
Aydın Yılmaz

Atatürk Göğüs Hastalıkları ve Göğüs Cerrahisi Eğitim ve Araştırma Hastanesi

TR-06280 Ankara (Turkey)

Tel. +90 312355 2110, Fax +90 3123552135

E-Mail aydnylmaz@yahoo.com 


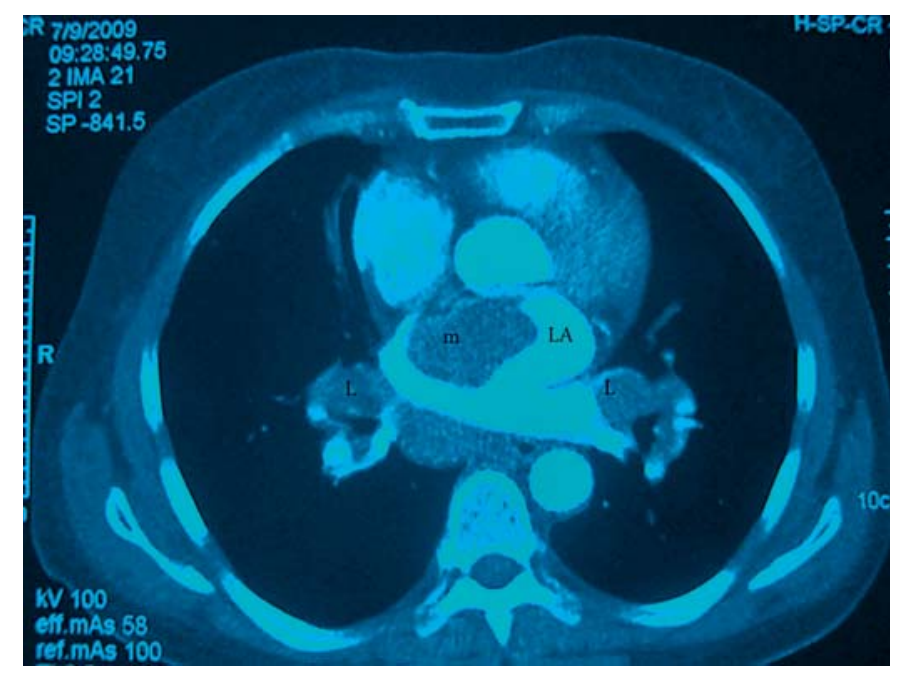

Fig. 1. Computerised tomography. $\mathrm{m}=$ Mass; LA = left atrium; $\mathrm{L}=$ lymphadenopathy.

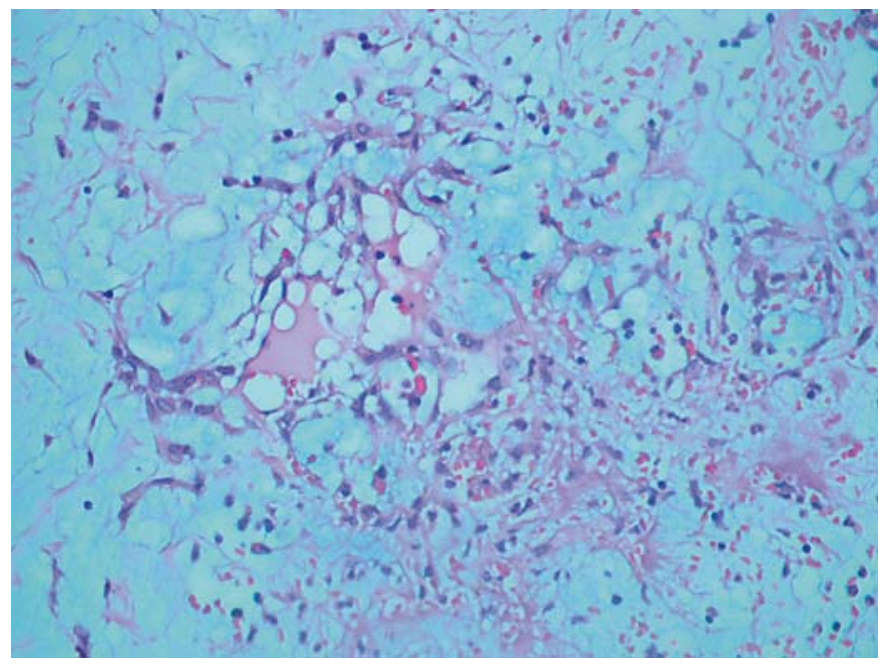

Fig. 3. Histopathology of myxoma.

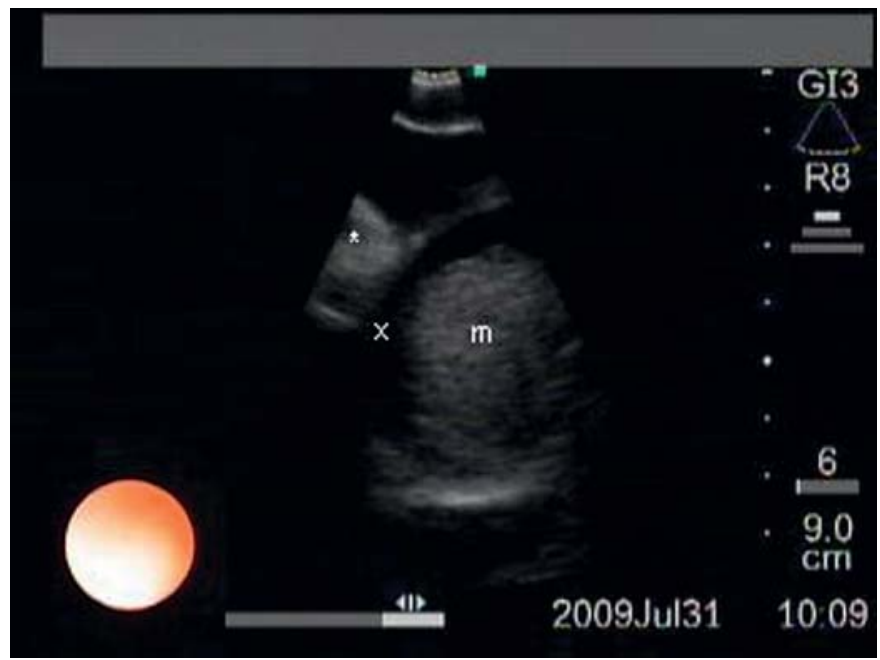

Fig. 2. Image obtained by EBUS. $\mathrm{m}=$ Mass.

References chi Y, Fujiwara T, Chiyo M, et al: The role of EBUS-TBNA for the diagnosis of sarcoidosis: comparisons with other bronchoscopic diagnostic modalities. Respir Med 2009;103: 1796-1800.

-2 Tremblay A, Stather DR, Maceachern P, Khalil M, Field SK: A randomized controlled trial of standard vs. endobronchial ultrasonography-guided transbronchial needle aspiration in patients with suspected sarcoidosis. Chest 2009;136:327-328.

-3 Aumiller J, Herth FJ, Krasnik M, Eberhardt R: Endobronchial ultrasound for detecting central pulmonary emboli: a pilot study. Respiration 2009;77:298-302.

4 Casoni GL, Gurioli C, Romagnoli M: Diagnosis of pulmonary thromboembolism with endobronchial ultrasound. Eur Respir J 2008;32:1416-1417. 